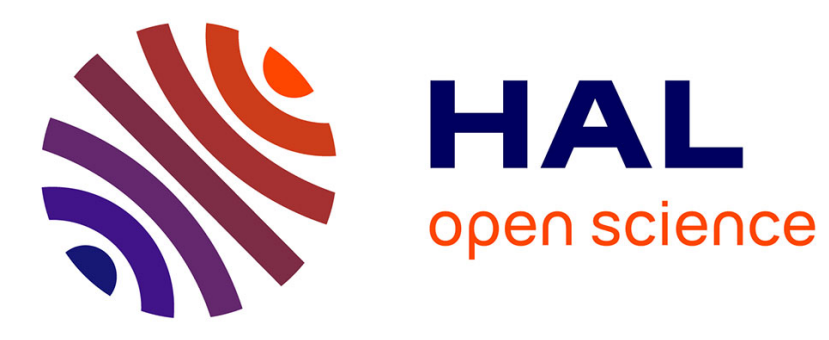

\title{
Limiting Energy Storage Cycles of Operation
}

\author{
Md Umar Hashmi, Ana Bušić
}

\section{To cite this version:}

Md Umar Hashmi, Ana Bušić. Limiting Energy Storage Cycles of Operation. 10th IEEE Green Technologies Conference (GreenTech 2018), Apr 2018, Austin, TX, United States. 10.1109/GreenTech.2018.00022 . hal-01806487

\section{HAL Id: hal-01806487 https://hal.science/hal-01806487}

Submitted on 3 Jun 2018

HAL is a multi-disciplinary open access archive for the deposit and dissemination of scientific research documents, whether they are published or not. The documents may come from teaching and research institutions in France or abroad, or from public or private research centers.
L'archive ouverte pluridisciplinaire HAL, est destinée au dépôt et à la diffusion de documents scientifiques de niveau recherche, publiés ou non, émanant des établissements d'enseignement et de recherche français ou étrangers, des laboratoires publics ou privés. 


\title{
Limiting Energy Storage Cycles of Operation
}

\author{
Md Umar Hashmi, and Ana Bušić
}

\begin{abstract}
Batteries are an expensive form of energy storage, therefore, must be operated in an efficient manner. Battery life is often described a combination of cycle life and calendar life. In this work we propose a mechanism to limit the number of cycles of operation over a time horizon in a computationally efficient manner. We propose a modification in an optimal arbitrage algorithm proposed in our previous work [1] to efficiently control the number of cycles of operation of a battery. The cycles of operation have to be tuned based on price volatility to maximize the battery life and arbitrage gains. We propose a mechanism to distinguish arbitrage returns.
\end{abstract}

\section{INTRODUCTION}

With increased share of power coming from Renewable Energy Sources (RES), the uncertainty in power networks is increasing. This variability makes the power, frequency and voltage regulation more challenging. Inverter based RES has small inertia compared to conventional synchronous power generators, reducing the capability of the future power grid to withstand perturbation. The future power network will need fast dynamic ancillary services to avoid additional infrastructure development in installing fast ramping power generators. Distributed energy storage devices such as batteries are suitable for assisting the grid because of its fast ramping capability. Authors in [2] highlight the diverse roles energy storage technologies can play in future power networks. Energy storage not only improves the reliability of power network but also facilitates arbitrage and increases the value of renewable energy sources in the energy markets. Authors in [3] point that battery owners participating in electricity markets should consider cycle aging of batteries. This is due to finite battery cycle life, which is affected by charge-discharge operational cycles, temperature etc. Using a case study on ISO New England energy and reserve markets, authors demonstrate that participants maximize their operational profit while considering cycle aging cost.

The variability in the price is due to the variable generation cost and demand and supply mismatch components caused due to scheduling delays and errors in forecast of RES. This variability in the price can be used by batteries for performing arbitrage. However, sometimes charge and discharge cycles generate very small revenue and it would be beneficial for the battery to be idle. Maximizing idle time would lower stress on the battery and maximize the cycle life of the battery [4].

Research supported by the French National Research Agency grant ANR16-CE05-0008, and by PGMO (Gaspard Monge Program for Optimization and operations research).

M.U.H. and A.B are with INRIA Paris and DI ENS, Ecole Normale Supérieure, CNRS, PSL Research University, Paris, France. Email: mdumar.hashmi@inria.fr
The key contributions are:

- Limiting cycles of operation: In this work we highlight how at the cost of small portion of arbitrage gains, the battery cycle life can be significantly improved.

- By introducing friction coefficient, $\eta_{\text {friction }}$ in energy arbitrage control we can efficiently control the cycles of operation. If the battery is operating more number of cycles per day then $\eta_{\text {friction }}$ is decreased so that the battery on average operates for lower number of cycles. Note the selection of $\eta_{\text {friction }}$ will governed by variability of price, number of cycles of operation in absence of any friction, i.e., $\eta_{\text {friction }}=1$.

- Distinguishing arbitrage returns: We present a mechanism to eliminate low returning transactions to maximize battery life.

The rest of the paper is organized as follows. In Section II we describe the cycle and calendar life of battery and list the typical values for power grid batteries. Section III summarizes the optimal arbitrage algorithm proposed in [1]. Section IV presents the mechanism to limit cycles of operation of a battery. Section V presents the numerical results. Section VI concludes the work.

\section{BATTERY LIFE}

There are two distinct, but inter-related ways that are used to measure the life of Li-ion batteries deployed in energy storage system applications for smart grid - calendar life and cycle life.

\section{A. Cycle Life}

One of the indexes which decides the life of operation is the rated cycles of operation of a battery. This information is often provided by manufacturers in their data-sheets. In this section we will enlist the values of the cycle of operation provided by the manufacturers under controlled environment. This value of cycles will with high probability lead to the end-of-life (EoL) of the battery. EoL is frequently defined as a state of the battery when the maximum capacity of the battery reduces to $80 \%$ of its rated initial capacity. In order to understand the typical cycle life of Li-ion based grid batteries, we summarize the cycle life information provided by the manufacturers in their data-sheets in Table [.

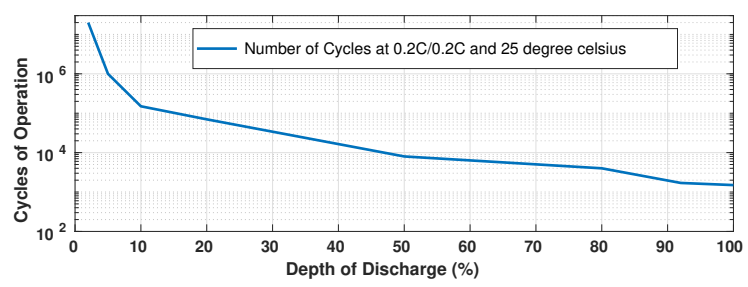

Fig. 1: Li-ion cycle of operation with DoD [11] 
TABLE I: Cycles of operation as listed in datasheets

\begin{tabular}{|c|c|c|}
\hline Manufacturer & Cycles of operation & Remarks \\
\hline C\&D Techno [5] & 4,300 cycles & $20^{\circ} \mathrm{C}, 80 \%$ DoD \\
\hline AES Advancion [6] & 2000 to 3000 & at $80 \%$ DOD \\
\hline LG Chem 6.4 [7] & $>6000$ & $90 \%$ DoD, $25^{\circ} \mathrm{C}$ \\
\hline QINOUS Li-ion [8] & 4000 cycles & $1 \mathrm{C} / 1 \mathrm{C}, 80 \%$ DoD, $25^{\circ} \mathrm{C}$ \\
\hline Tesla Powerwall 1 [9] & 5000 cycles & daily cycle application \\
\hline Tesvolt & 8000 cycles & for 70\% DoD \\
Li-phosphate [10] & 5000 cycles & for $90 \%$ DoD \\
\hline Forsee Power & 6000, no aging & 25 deg.C, $70 \%$ DOD \\
HE48 [11] & 5000, with aging & $25^{\circ} \mathrm{C}, 2$ cycles/day \\
\hline aentron Li-ion [12] & 4400, with aging & $25^{\circ} \mathrm{C}, 1$ cycles/day \\
\hline Bosch Storage [13] & 3000 & $50 \%$ DoD, $20^{\circ} \mathrm{C}$ \\
\hline REFU [14] & 4500 & - \\
& 6000 & $80 \%$ DoD, $20^{\circ} \mathrm{C}$, \\
& & max discharge $=0.5 \mathrm{C}$ \\
\hline
\end{tabular}

The factors affecting the rated cycles of operation are:

- Battery type: Chemical composition of the battery,

- Depth of discharge (DoD): Operational cycles,

- Temperature should be maintained,

- Ramp rate: affects the stress on the battery,

- Cycles per day.

Fig. 11 shows the effect of number of cycles of operation with variation in DoD. It should be noted that 10 cycles of $10 \%$ DoD will be equal to 1 cycle of $100 \%$ DoD, in terms of energy exchange.

\section{B. Calendar Life}

Calendar life refers to the number of years the battery is expected to last till the battery will reach EoL. It is independent of how much the battery is charged and discharged. However, calendar life is dependent on the state of charge of the battery and the temperature.

TABLE II: Calendar Life as listed in datasheets

\begin{tabular}{|c|c|}
\hline Manufacturer & Calendar life and Remarks \\
\hline AES Advancion [6] & 7-8 years Lifespan \\
\hline Evolion Li-ion battery $[15$ & $\begin{array}{l}\text { at } 20 \text { deg. } \mathrm{C} \text { is } 20 \text { years } \\
\text { at } 40 \mathrm{deg} . \mathrm{C} \text { is }>10 \text { years }\end{array}$ \\
\hline LG Chems RESU 6.4 EX [7] & at 25 deg. $\mathrm{C}$ is $>10$ years \\
\hline Tesla Powerwall $2[9$ & warranty of 10 years \\
\hline Tesvolt Li-phosphate [10] & 10 years \\
\hline Forsee Power Li-ion HE48 & 10 years \\
\hline aentron Off grid Li-ion \12】 & 10 yr. at 20 deg. C, Warranty 5 yr. \\
\hline Bosch Storage Solutions [13] & $>10$ years \\
\hline BYD $\lfloor 16 \square$ & Warranty of 5 years \\
\hline
\end{tabular}

Table III indicate that the typical value of calendar life is around 10 years. The calendar life deteriorates drastically with temperature as shown in Table $\mathrm{II}$ for Evolion Li-ion battery.

The life of a battery will be a function of cycle life and calendar life. If the battery operates more cycles per unit of time then the battery EoL will be achieved due to cycle life limitations and vice versa. Data-sheet [17] shows how the calendar life of the battery is a function of SoC level and temperature. An interesting observation is that a high SoC level affects the calendar life drastically at high temperatures. It can be observed that below $35^{\circ} \mathrm{C}$ expected life is independent of SoC. In this work we assume temperature is controlled and $\mathrm{SoC}$ is regulated in the optimal band of operation.

\section{Optimal Storage Control}

In a commodity market, arbitrage can be performed if the price of that commodity varies in time. Often, the buy and sell decisions are coupled in time because of the finite size of the buffer/capacity/inventory, where the commodity is stored. Similarly, when energy storage devices perform arbitrage, the buy and sell decisions are coupled because of the finite storage size; a decision to buy or sell in the present time instant will influence the potential to charge or discharge in future.

The total duration, $T$, of operation is divided into $N$ equal steps, where in each step $i \in\{1, \ldots, N\}$ the price of electricity is denoted as $p_{i}$. The sampling time is denoted as $h$. The efficiency of charging and discharging of the battery are denoted by $\eta_{\mathrm{ch}} \in(0,1]$ and $\eta_{\text {dis }} \in(0,1]$, respectively. We denote the change in the energy level of the battery at $i^{\text {th }}$ instant by $x_{i}=h \delta_{i}$, where $\delta_{i}$ denotes the storage ramp rate at $i^{\text {th }}$ instant; $\delta_{i}>0$ implies charging and $\delta_{i}<0$ implies discharging. Amount of energy that comes from the battery at $i^{\text {th }}$ instant is given by $s_{i}=\frac{1}{\eta_{\mathrm{ch}}}\left[x_{i}\right]^{+}-\eta_{\mathrm{dis}}\left[x_{i}\right]^{-}$.

Storage Constraints: The battery has limited capacity. We incorporate the battery capacity constraints by imposing $b_{i} \in$ $\left[b_{\min }, b_{\max }\right], \forall i$, where $b_{\min }, b_{\max }$ is the minimum and the maximum battery charge level. In operating Li-ion battery it should be ensured that it is never over-charged or overdischarged. The instantaneous battery charge level is given as $b_{i}=b_{i-1}+x_{i}$.

The ramp rate constraint is given as $\delta_{i} \in\left[\delta_{\min }, \delta_{\max }\right], \forall i$, where $\delta_{\min } \leq 0, \delta_{\max } \geq 0$ are the minimum and the maximum ramp rates $(\mathrm{kW})$. The change in battery charge level $x_{i} \in$ $\left[X_{\min }, X_{\max }\right]$, where $X_{\min }=\delta_{\min } h$ and $X_{\max }=\delta_{\max } h$.

An optimal control problem for an energy storage device such as a battery is proposed in [18], [19] using convexity property of the optimization function and saddle point inequality. Authors in [1] propose optimal energy arbitrage algorithm under time varying electricity prices. In this work it is shown that a time horizon of optimization can be subdivided into sub-horizons. In each of these sub-horizons, the shadow price is a function of price levels in a sub-horizon and is independent of all past and future sub-horizons. This value of the shadow price is altered only when the battery capacity reaches its maximum or minimum permissible charge levels. Based on the value of shadow price in a sub-horizon, the optimal control decisions are selected depending on the level of price of electricity at that instant.

The threshold based structure of the optimal solution is presented in Remark 1 .

Remark 1. The optimal control decision $x_{i}^{*}$ in the $i$ th instant minimizes the function $C_{\text {storage }}^{(i)}(x)-\mu_{i}^{*} x$ for $x \in\left[X_{\min }, X_{\max }\right]$. 
The optimal decision $x_{i}^{*}(\mu)$ is

$$
x_{i}^{*}(\mu)= \begin{cases}X_{\min }, & \text { if } \mu<p_{\mathrm{dis}}(i), \\ {\left[X_{\min }, 0\right],} & \text { if } \mu=p_{\mathrm{dis}}(i), \\ 0, & \text { if } p_{\mathrm{ch}}(i)>\mu>p_{\mathrm{dis}}(i), \\ {\left[0, X_{\max }\right],} & \text { if } \mu=p_{\mathrm{ch}}(i), \\ X_{\max }, & \text { if } \mu>p_{\mathrm{ch}}(i),\end{cases}
$$

where $p_{\mathrm{ch}}(i)=p_{i} / \eta_{\mathrm{ch}}, p_{\text {dis }}(i)=p_{i} \eta_{\text {dis }}, C_{\text {storage }}^{(i)}\left(x_{i}\right)=s_{i} p_{i}$ and $\mu$ represents the shadow price of the transaction.

Note for $\mu=p_{\mathrm{ch}}(i)$ or $\mu=p_{\mathrm{dis}}(i), x_{i}^{*}(\mu)$ takes an envelope of values and for any other value of $\mu$ it is a singleton set.

In order to find optimal decisions among an envelope of possible solutions based on the price variations, the Backward Step algorithm is used one time. The details of the algorithm can be found in prior work [1].

\section{Limiting CyCles OF OPERATION}

In Section II we discussed that the cycles of operation is one of the primary indicators of battery life. In other words, if the battery is used a lot then the battery will last less. To maximize the operational life, the average number of cycles of operation per unit of time $\left(I_{o p}\right)$ should be set to

$$
I_{o p}=\frac{\text { Cycle Life }}{\text { Calendar Life }} .
$$

EoL of a battery operating more than $I_{o p}$ will be caused by the limitation on cycle life of the battery, implying the battery is over-used. If the battery is under-used, EoL will be caused by the calendar life. We assume that if cycle life equals calendar life of the battery than the operational life the battery is maximized. This criterion will be met if battery operates $I_{O p}$ cycles per unit time on average, shown in Eq. 2 .

Note the volatility across all days in a year can vary drastically, implying battery should perform more cycles when the volatility is high. The friction coefficient ideally should be selected adaptively ensuring maximizing gains and battery's operational life.

We propose limiting the operation of the battery by adding friction in mode changes for the battery. Adding friction will ensure that the battery does not operate for lower returns. This idea of creating dead-band of no operation is motivated by Eq. 11 The threshold based structure of the optimal solution indicates that the optimal decision for the battery when the condition $p_{\mathrm{ch}}(i)>\mu>p_{\mathrm{dis}}(i)$ is true, is to do nothing. This band signifies the additional profit the charge discharge cycle of a battery should make in order to compensate the losses incurred due losses in charging and discharging. Increase of this band will indicate eliminating low returns transactions in arbitrage. We define modified charging and discharging cost as a function of friction coefficient denoted as

$$
\begin{gathered}
p_{\mathrm{ch}}^{L}(i)=p_{\mathrm{ch}}(i) / \eta_{\text {friction }}=\frac{p_{i}}{\eta_{\mathrm{ch}} \eta_{\text {friction }}} \\
p_{\text {dis }}^{L}(i)=p_{\text {dis }}(i) \eta_{\text {friction }}=p_{i} \eta_{\text {dis }} \eta_{\text {friction }}
\end{gathered}
$$

The threshold based structure of the solution is modified as

$$
x_{i}^{*}(\mu)= \begin{cases}X_{\min }, & \text { if } \mu<p_{\mathrm{dis}}^{L}(i), \\ {\left[X_{\min }, 0\right],} & \text { if } \mu=p_{\mathrm{dis}}^{L}(i), \\ 0, & \text { if } p_{\mathrm{ch}}^{L}(i)>\mu>p_{\mathrm{dis}}^{L}(i), \\ {\left[0, X_{\max }\right],} & \text { if } \mu=p_{\mathrm{ch}}^{L}(i), \\ X_{\max }, & \text { if } \mu>p_{\mathrm{ch}}^{L}(i),\end{cases}
$$

The selection of $\eta_{\text {friction }}$ will be governed by: volatility of the price, maximizing operational life of the battery and arbitrage gains. Note the value of $\eta_{\text {friction }} \in[0,1]$. The control of $\eta_{\text {friction }}$ should only be considered if the cycles of operation per day is higher than $I_{o p}$.

\section{Numerical Results}

In this section we present a numerical example demonstrating the effect of friction coefficient on arbitrage gains, number of cycles of operation and the shadow price of transaction. The battery parameters used for the numerical evaluation is listed in Table III. Consider the battery has a cycle life of 6000 cycles

\section{TABLE III: Battery Parameters}

\begin{tabular}{|c|c||c|c|}
\hline Parameter & Value & Parameter & Value \\
\hline$\delta_{\max }$ & $0.5 \mathrm{~kW}$ & $\delta_{\min }$ & $-0.5 \mathrm{~kW}$ \\
\hline$b_{\max }$ & $1 \mathrm{kWh}$ & $b_{\min }$ & $0.1 \mathrm{kWh}$ \\
\hline$\eta_{\mathrm{ch}}$ & 0.95 & $\eta_{\text {dis }}$ & 0.95 \\
\hline$h$ & 0.25 hour & $b_{0}$ & $0.1 \mathrm{kWh}$ \\
\hline
\end{tabular}

and calendar life of 10 years. The optimal number of cycles the battery should operate per day should be $I_{o p}=1.644$ per day, using Eq. 2. Real-time 15-minute locational marginal price data for 21st December, 2016 from NYISO [20] is used for simulation analysis. The electricity price is plotted in Fig. 2. Fig. 3 shows the variation of cycles of operation

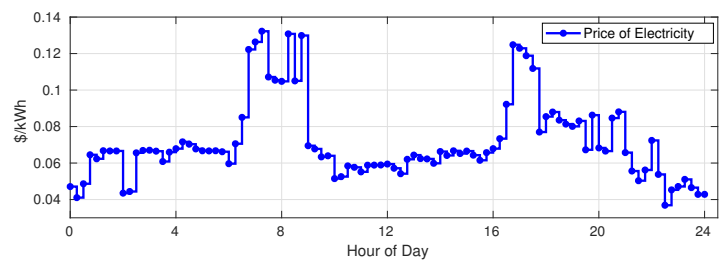

Fig. 2: Price of Electricity NYISO [20]

and arbitrage gains with friction coefficient. When friction coefficient is 1 implies battery operates more and the arbitrage gains are higher. As the coefficient is reduced the decrease in gains and cycles of operation can be observed. For $I_{o p}$ cycles per day, the optimal value of friction coefficient for this numerical example is $\eta_{\text {friction }_{o p t}}=0.855$ as shown in Fig. 3. Note that for achieving $I_{o p}$ cycles the reduction in arbitrage gains is $\approx 10 \%$ and the cycles of operation decreases by $\approx 36 \%$. A risk averse user may prefer to maximize it's current gains, for example for $\eta_{\text {friction }}=0.928$, the reduction in gains is $1.47 \%$ and the reduction in cycles of operation will be $11.7 \%$. Fig. 4 shows the variation of shadow price 


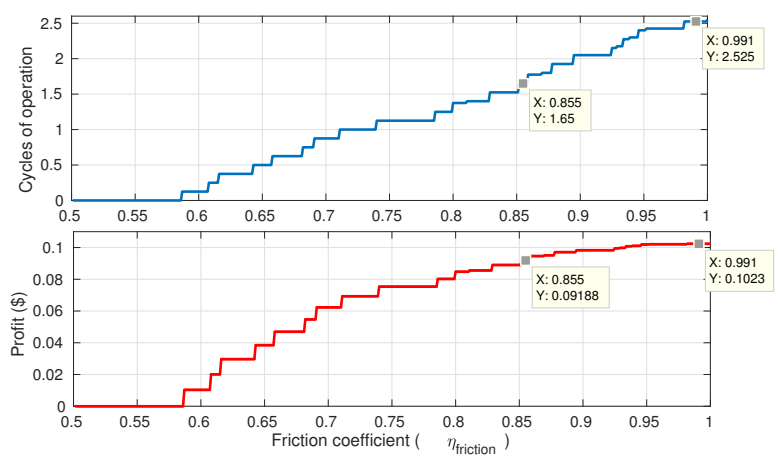

Fig. 3: Variation of cycles and gains with $\eta_{\text {friction }}$

across the time horizon of 1 day as the friction coefficient is varied. Note as the friction coefficient is reduced, the shadow price converges to a single level. Fig. 5 shows the variation

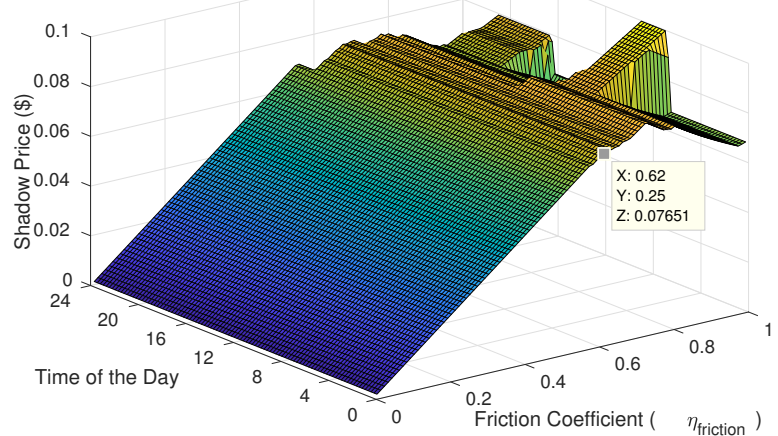

Fig. 4: The shadow price in a day vary with $\eta_{\text {friction }}$

of ramp rate of the battery with $\eta_{\text {friction }}$. On comparing Fig. 5 with respect to price variations in Fig. 2, it is evident that battery operates only when the gains are significantly higher for lower values of $\eta_{\text {friction. }}$. As the $\eta_{\text {friction }}$ is reduced the battery operates only around midnight to charge in order to discharge during morning peak and during evening peak. The friction coefficient distinguishes arbitrage gains based on the returns. Inclusion of $\eta_{\text {friction }}$ ensures battery operates for only when the gains are high enough.

\section{CONCLUSION}

We propose a mechanism to compare arbitrage gains and cycles of operation for a battery. The users can tune the coefficient of friction according the price volatility over a period to maximize operational life of a battery and its arbitrage gains. The inclusion of friction coefficient ensures that low returning transactions are eliminated and battery operates only when returns are higher.

\section{REFERENCES}

[1] M. U. Hashmi, A. Mukhopadhyay, A. Bušić, and J. Elias, "Optimal control of storage under time varying electricity prices," IEEE International Conference on Smart Grid Communications, 2017.

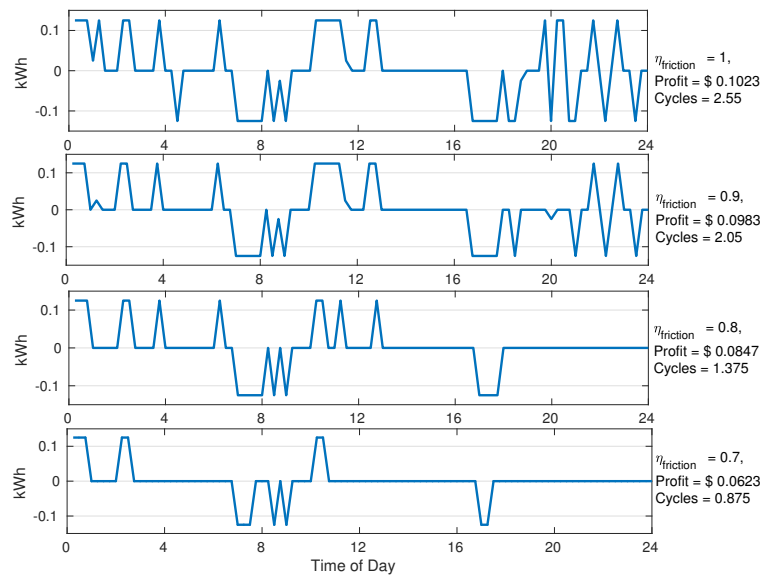

Fig. 5: Variation of ramp rate of the battery with $\eta_{\text {friction }}$

[2] K. Divya and J. Østergaard, "Battery energy storage technology for power systemsan overview," Electric Power Systems Research, vol. 79, no. 4, pp. 511-520, 2009.

[3] B. Xu, J. Zhao, T. Zheng, E. Litvinov, and D. S. Kirschen, "Factoring the cycle aging cost of batteries participating in electricity markets," IEEE Transactions on Power Systems, 2017.

[4] A. Bušić, M. U. Hashmi, and S. Meyn, "Distributed control of a fleet of batteries," in American Control Conference (ACC), 2017. IEEE, 2017, pp. 3406-3411.

[5] CDTechno, "Featherweight lithium-ion battery li tel 48-170 c," 2017. [Online]. Available: http://www.cdtechno.com/pdf/lit/12_1093_1214.pdf

[6] AES, "Advancion energy storage for the grid," 2017. [Online]. Available: http://aesenergystorage.com/wp-content/uploads/ 2017/01/010517-Advancion-4-Brochure.pdf

[7] LG-Chem, "Resu 6.4 ex," 2017. [Online]. Available: https://drive. google.com/open?id=0BxK92uSDJ7PEbFFLamRTTXA2NFk

[8] QINOUS, "Qinous ess compact, medium, large," 2017. [Online]. Available: https://drive.google.com/open?id= 0BxK92uSDJ7PEVmJUcWpQcHYwVkU

[9] Wikipedia, "Tesla-powerwall." [Online]. Available: https://en.wikipedia. org/wiki/Tesla_Powerwall

[10] Tesvolt, "Tps energy storage," 2017. [Online]. Available: https: //drive.google.com/open?id=0BxK92uSDJ7PETGFubTFQLXg5bnM

[11] ForseePower, "Lithium-ion he 48," 2017. [Online]. Available: https: //drive.google.com/open?id=0BxK92uSDJ7PENlczWURjelNnUlU

[12] Aentron, "Off grid battery system," $2017 . \quad$ [Online]. Available: http://www.aentron.com/wp-content/uploads/2017/05/OFF_ GRID_BATTERY_SYSTEM_EN.pdf

[13] Bosch, "Bosch energy storage solutions," 2017. [Online]. Available: http://boschenergystoragesolutions.resource.bosch.com/ media/bess/pdfs/BoschStorageSolution_Power_EN.pdf

[14] REFU-Elektronik-GmbH, "Refubox rb-003-003-001-0300," 2017. [Online]. Available: http://www.refu-energy.de/uploads/tx_edxproductman/ 1405_Datenblatt_eng_REFUbox_AnsichtEinzels.pdf

[15] Saft-Batteries, "Evolion, proven ultra-compact solution for on and off-grid installations," 2017. [Online]. Available: http://www.anu-co. com/DataSheets/Saft\%20Batteries/Evolion.pdf

[16] BYD, "Byd home based energy storage solution," 2017. [Online]. Available: http://www.byd.com/energy/download/DESS/ English-DESS\%20Brochure_2013_02_05.pdf

[17] Saft, "Li-ion battery life," 2017. [Online]. Available: https://drive. google.com/open?id=0BxK92uSDJ7PEbHVjRGk3MXE0YUE

[18] J. R. Cruise, R. J. Gibbens, and S. Zachary, "Optimal control of storage for arbitrage, with applications to energy systems," in Information Sciences and Systems (CISS), 2014 48th Annual Conference on. IEEE, 2014, pp. 1-6.

[19] J. Cruise, L. Flatley, R. Gibbens, and S. Zachary, "Optimal control of storage incorporating market impact and with energy applications," arXiv preprint arXiv:1406.3653, 2014.

[20] NYISO, "Real time locational marginal price," Online, https://tinyurl. com/2flowo6 2016. 